\title{
MIXED INVEX EQUILIBRIUM PROBLEMS WITH GENERALIZED RELAXED MONOTONE AND RELAXED INVARIANT PSEUDOMONOTONE MAPPINGS
}

\author{
Bijaya Kumar Sahu, Sabyasachi Pani and R. N. Mohapatra
}

\begin{abstract}
In this paper, we introduce generalized relaxed monotone mappings and relaxed invariant pseudomonotone mappings for bi-functions. By using KKM technique, we establish certain existence results for mixed invex equilibrium problems with the generalized relaxed monotone mappings and some of the results for invex equilibrium problems with the relaxed invariant pseudomonotone mappings in Banach spaces.
\end{abstract}

Mathematics subject classification (2010): 90C33, 47J20, 47J30, 47H05.

Keywords and phrases: Equilibrium problem, generalized relaxed $\eta-\alpha$ monotonicity, relaxed $\rho-\theta$ invariant pseudomonotonicity, KKM mappings.

\section{REFERENCES}

[1] A. Arunchai, S. Plubtieng And C. F. Wen, Existence theorems for relaxed $\eta$ - $\alpha$ pseudomonotone and strictly $\eta$-quasimonotone generalized variational-like inequalities, Journal of Inequalities and Applications, 2014, 1 (2014), 442.

[2] M. R. BAI, S. Z. ZHOU AND G. Y. Ni, On the generalized monotonicity of variational inequalities, Computers \& Mathematics with Applications, 53, 6 (2007), 910-917.

[3] M. R. BAI, S. J. Zhou AND G. Y. NI, Variational-like inequalities with relaxed $\eta-\alpha$ pseudomonotone mappings in Banach spaces, Applied Mathematics Letters, 19, 6 (2006), 547-554.

[4] M. BIANCHI AND S. SCHAIBLE, Equilibrium problems under generalized convexity and generalized monotonicity, Journal of Global Optimization, 30, 2 (2004), 121-134.

[5] E. Blum AND W. OetTli, From optimization and variational inequalities to equilibrium problems, Mathematics Student-India, 63, 1 (1994), 123-145.

[6] O. Chadli, Z. ChBANI, AND H. RiAhI, Equilibrium problems with generalized monotone bifunctions and applications to variational inequalities, Journal of Optimization Theory and Applications, 105, 2 (2000), 299-323.

[7] K. FAN, A generalization of Tychonoff's fixed point theorem, Mathematische Annalen, 142, 3 (1961), 305-310.

[8] A. Farajzadeha, S. Plubtiengb and A. Plubtiengb, On the existence of solutions of generalized equilibrium problems with $\alpha-\beta-\eta$-monotone mappings, Journal of Nonlinear Sciences \& Applications, 9, 10 (2016), 5712-5719.

[9] Z. LIU AND S. ZENG, Equilibrium problems with generalized monotone mapping and its applications, Mathematical Methods in the Applied Sciences, 39, 1 (2016), 152-163.

[10] N. K. MAHATO AND C. NAHAK, Equilibrium problems with generalized relaxed monotonicities in Banach spaces, Opsearch, 51, 2 (2014), 257-269.

[11] N. K. MAHATO AND C. NAHAK, Variational-Like Inequalities and Equilibrium Problems with Generalized Monotonicity in Banach Spaces, Advances in Operations Research, 2012, (2012), 15 pages.

[12] S. NANDA AND S. PANI, An existence theorem of Walrasian equilibrium, Applied mathematics letters, 16, 8 (2003), 1279-1281.

[13] G. PAnY, R. N. Mohapatra AND S. PANI, A class of Mixed variational-like inequalities and equilibrium problems in Banach spaces, Journal of Inequalities and Special Functions, 7, 4 (2016), 241252. 
[14] G. Pany And S. PAni, On Mixed Equilibrium Problems in Banach Spaces, PanAmerican Mathematical Journal, 26, 3 (2016), 12-24.

[15] B. K. SAhU AND S. PANi, Equilibrium Problems with Generalized Relaxed $\eta-\alpha$-pseudomonotone and Strictly $\eta$-quasimonotone Mappings in Banach Spaces, Communications on Applied Nonlinear Analysis, 25, 2 (2018), 80-91.

[16] W. SintUNAVARAT, Mixed equilibrium problems with weakly relaxed $\alpha$-monotone bifunction in Banach spaces, Journal of Function Spaces and Applications, 2013, (2013), 5 pages.

[17] R. U. VERMA, On monotone nonlinear variational inequality problems, Commentationes Mathematicae Universitatis Carolinae, 39, 1 (1998), 91-98.

[18] R. U. VERMA, Variational inequalities involving strongly pseudomonotone hemicontinuous mappings in nonreflexive Banach spaces, Applied Mathematics Letters, 11, 2 (1998), 41-43. 